\title{
Have our strictures changed? Analysis of Current Characteristics and Management of Urethral Stricture Disease in Zaria, Nigeria
}

Nasir Oyelowo ( $\square$ nasiroyelowo@gmail.com )

Ahmadu Bello University Zaia https://orcid.org/0000-0003-2356-6878

Muhammed Ahmed

Ahmadu Bello University

Ahmad Bello

Ahmadu Bello University

Ahmad Tijani Lawal

Ahmadu Bello University

Husseni Yusuf Maitama

Ahmadu Bello University

Muhammad Salihu Muhammad

Federal Medical Center Bida

Khalifa Abdulsalam

Federal Teaching Hospital Gombe

lawal Bola Bilyaminu

Ahmadu Bello University

Jemila Olagunju

Ahmadu Bello University Teaching Hospital

Research article

Keywords:

Posted Date: September 10th, 2019

DOI: https://doi.org/10.21203/rs.2.14252/v1

License: (c) (i) This work is licensed under a Creative Commons Attribution 4.0 International License.

Read Full License 


\section{Abstract}

Introduction: Urethral stricture is a common cause of lower urinary tract symptoms in the middle aged and elderly men. Its presentation and management is closely linked with its etiology and this varies across geographical regions of the world as well as over time. We hereby review the etiology, characteristics and presentation of men with urethral strictures in a tertiary hospital in northern Nigeria over a year and compare it with previous studies in the region. Patients and Methods The study was a prospective study from January-December 2016, all patients with urethral strictures and who consented to the study were enrolled into the study. Data was collected using a structured study profoma and analyzed using SPSS version 23. Results The mean age was 44.1 years with a range of 13-71 years. The bulbar urethra was the site of most strictures with a frequency of $65 \%$. The etiology was infection in majority of the patients with a frequency of $53.3 \%$. Post traumatic strictures occurred in $33.3 \%$ while iatrogenic and catheter - Induced strictures were seen in $7.1 \%$ and $6 \%$ respectively. $88 \%$ had no previous intervention for the stricture prior to presentation. The complications from urethral strictures observed in the patients were acute urinary retention in $83.4 \%$ urethrocutaneous fistulae in $2.4 \%$ and urosepsis in $1.2 \%$ of the patients. $11 \%$ presented with no complication. $68 \%$ of these patients were managed by excision and end to end anastomosis, $15 \%$ had a penile pedicled flap $12 \%$, a buccal mucosa graft urethroplasty and $5 \%$ with staged urethroplasty The trends in etiology of urethral stricture disease in the region reported is: Ahmed etal in zaria (1990) Infection accounted for $66.50 \%$, post traumatic stricture $31.50 \%$. Ntia et al Sokoto (2006)found infection as aetiology in $44.70 \%$ and post-traumatic strictures in $47.40 \%$. Ofoha et al in Jos however found Infection in $53.30 \%$ and post traumatic $40.30 \%$ Conclusion Though there is a gradual rise in post-traumatic and iatrogenic strictures in our environment, Post inflammatory strictures still predominates. It is however infrequently accompanied by fistulae as seen decades ago. These strictures are mostly long segments single bulbar strictures

\section{Introduction}

Urethral strictures are narrowing and loss of distensibility of the urethral due to fibrosis of the corpous spongiosum from inflammation or ischemia[1]. Strictures are common and always have been a cause of lower urinary tract symptoms in the middle aged and elderly[2].

It's a disease of both the developing and developed world; though the etiology varies amongst them[35].The etiology also seems to evolve overtime within the same region. In the developed world, this was attributed to better treatment of sexually transmitted diseases, surge in endourological procedures and industrialization resulting in less of post inflammatory strictures and more of iatrogenic as well as traumatic strictures. However in the developing world, the picture is different with some reports of predominance of post inflammatory strictures while others reported iatrogenic and post traumatic strictures.

The emphasis on the etiology of strictures is because it typically gives the characteristics of the stricture which is the basis of the choice of treatment and subsequently prognosis[6]. 
Post inflammatory strictures are known to be characterized as multiple, long segment, incomplete strictures with severe spongiofibrosis. Substitution urethroplasties may be indicated for these strictures typically with a penile skin flap or a buccal mucosa graft. Success rate is usually in the range of $70-80 \%$ [7].

Traumatic strictures are however usually that of a short segment, single strictures with mild to moderate spongiofibrosis and an excision and end-end anastomosis may suffice with a success rate of $95-99 \%$. Internal urethrotomies may also be done in patients with short segment incomplete strictures.

We hereby review the etiology, stricture characteristics, presentation and management of men with urethral strictures in a tertiary hospital in northern Nigeria over a year and compare it with previous studies in the region.

\section{Patients And Methods}

The study was conducted over a year period from January - December 2016. All patients with urethral stricture managed within the study period and who consented to the study were enrolled into the study while patients with strictures from failed hypospadias repair and stenosis at the posterior urethra were excluded. Furthermore, approval from the ethical committee was also obtained. Patients had clinical and radiological evaluation ( sonourethrography and retrograde urethrogram ) to characterize the stricture. Data was collected on a study profoma and analysed using SPSS version 22. Electronic data base was searched to review studies on etiology, presentation and management of strictures for comparison.

\section{Results}

A total of 84 patients were managed during the study period. The mean age of the patients was 44.19 years with standard deviation of 12.54, and a range of 13-71 years. The age interval $30-39$ years accounted for most of the patients 24 (28.6\%). The age distribution is as shown in the figure below. (see Figure 1)

Most of the patients were traders 21 (25\%). Men, who are members of the armed forces constituted 13 $(15 \%)$ of the patients while students were the least of the study group $8(9.5 \%)$. The distribution of the occupation of the patients is shown in the table 1 below

Table 1: Occupations of patients in the study 


\begin{tabular}{lcc}
\hline Occupation & Frequency & Percentage \\
\hline Trading & 21 & 25.0 \\
Civil servant & 18 & 21.4 \\
Farming & 14 & 16.7 \\
Armed forces & 13 & 15.5 \\
Unemployed & 10 & 11.9 \\
Student & 8 & 9.5 \\
Total & 84 & 100 \\
\hline
\end{tabular}

All the patients had lower urinary tract symptoms. Acute urinary retention was seen in $70(83.3 \%)$, $2(2.4 \%)$ had previous history of urethrocutaneous fistulae and a patient $(1.2 \%)$ had resolved Urosepsis. $11(13.1 \%)$ had no added symptom apart from Lower urinary tract symptoms. 6 The aetiology of stricture found during history taking is shown in the figure below with poorly treated urethritis been the commonest cause of stricture seen responsible for more than half (53.6\%) of the strictures studied. None of the patients had idiopathic cause.

$7(8.3 \%)$ patients had previous failed urethroplasties, $2(2.4 \%)$ patients had previous DVIU and a patient $(1.2 \%)$ had previous urethral dilations. $74(88.1 \%)$ had no previous treatment. $72(85.7 \%)$ patients had a Suprapubic cystostomy at presentation, $14(16.7 \%)$ patients had demonstrable periurethral induration and $8(9.5 \%)$ patient had urethral discharge. $4(4.8 \%)$ had none of these on examination.

The characteristics of the strictures found in the patients are shown in the table 2 below with the bulbar urethra being the commonest site of the strictures seen in 56(65\%) patients

Table 2.0 Characteristics of the strictures in patients

\begin{tabular}{|llc|}
\hline \multicolumn{2}{|c|}{ CHARACTERISTICS OF THE STRICTURE } & FREQUENCY \\
LENGTH & $\leq 2 \mathrm{~cm}$ & $36(43 \%)$ \\
& $>2 \mathrm{~cm}$ & $48(57 \%)$ \\
SITE & Penile & $21(25 \%)$ \\
& Peno-bulbar & $18(21 \%)$ \\
\multirow{2}{*}{ Number } & Bulbar & $56(65 \%)$ \\
& Single & $76(90 \%)$ \\
Complications & Multiple & $8(10 \%)$ \\
& Acute Urinary Retention & $70(83.3 \%)$ \\
& Urethrocutaneous Fistulae & $2(2.4 \%)$ \\
& Urosepsis & $1(1.2 \%)$ \\
\hline
\end{tabular}


Majority of the patients $57(67.9 \%)$ had excision of the strictures and end-end anastomosis, Substitution Urethroplasty (a pedicled flap or buccal mucosa graft) and staged urethroplasty was done in others. The frequency is as shown in the pie chart below. (See Figure 3)

\section{Discussion}

Urethral stricture is currently a disease of the middle aged worldwide. The mean age at presentation of patients with strictures is similar in both the developed and developing countries usually in the fifth decade[2,4,8,9]. We found a mean age of 44.1 years which is similar to the age found recent studies in china, UK, Italy India and Senegal[10]. This is in contrast to the previous perception as earlier literatures on strictures reported a higher prevalence in the elderly.

The etiologies however differ in both the developed and developing countries overtime with more of post traumatic and iatrogenic strictures noted in most developed countries and a predominance of post inflammatory strictures in the developing countries. Prevention and adequate treatment of urethritis has significantly reduced the incidence of post inflammatory strictures in the developed countries[11,12]. In the developing countries post inflammatory strictures still exist due to lack of adequate awareness of the effect of sexually transmitted diseases, low socioeconomic status and poor health seeking behavior[13]. A significant number of those who present to the health care centers are prone to poor treatment of the urethritis either due to inadequate dosage of the antibiotics, inadequate duration of treatment or use of drugs with limited efficacy resulting in recurrent urethritis and stricture[14]. Hence the prevalence of urethritis, and post inflammatory strictures are still relatively high in some developing countries.

In our study, we found the most common cause of stricture as post inflammatory. This is largely due to the above reasons. Post traumatic stricture is on the rise largely due to motor vehicular crash as well as social violence and conflicts in most part of the country with patients presenting with strictures amongst other injuries from explosion of land mines or gunshot to the perineum. Ahmed et al in 1989 found a similar but higher rates of post inflammatory strictures $(66.5 \%)$ in our center compared to our study where post inflammatory strictures now account for (53.3\%)[15]. The incidence of post traumatic strictures has however not remarkably changed; $31.7 \%$ by Ahmed et al in 1989 and we found $33.3 \%$ in this study. However, most of the strictures were multiple in their series and managed by dilation (85\%) and urethroplasty ( $26 \%$ ) as compared to our study where only $10 \%$ were multiple and all our strictures are now managed by urethroplasty.

In other parts of Nigeria, post inflammatory strictures still constitute a significant number of their strictures as reported by Ekeke, Ntia, Tijani and Ofoha[11,12,16] . Although in some of these studies stenosis of the posterior urethra from pelvic fractures were included as post traumatic strictures which we clearly excluded in this study due to the current restriction of the term urethral strictures to the anterior urethra. 
The trends in etiology of urethral stricture disease in the region reported is: Ahmed etal in zaria (1990) Infection accounted for $66.50 \%$, post traumatic stricture $31.50 \%$. Ntia et al Sokoto (2006)found infection as aetiology in $44.70 \%$ and post-traumatic strictures in $47.40 \%$. Ofoha et al in Jos however found Infection in $53.30 \%$ and post traumatic $40.30 \%$

It's also interesting to note that though most of our strictures are post inflammatory, they are usually single and bulbar with excision and anastomotic urethroplasty feasible in $68 \%$ of our patients. These characteristics of the strictures as well as the low incidence of perineal abscess and fistulae in this study may reflect an improvement in the awareness of sexual transmitted disease and its complications, primary health care services and possibly treatment of urethritis though with a room for improvement. Substitution urethroplasty either as buccal mucosa graft or pedicle penile flap was required in $27 \%$ and staged urethroplasty in only $5 \%$, a reflection of the aim of management of our strictures which is cure.

Therefore, though we found a slower decline in the incidence of post inflammatory strictures in our environment as compared to other parts of the world, the characteristics of the strictures have changed as well as its management over time. Excision and anastomotic urethroplasty a procedure with the best success rate in management of strictures is feasible in most of our patients.

\section{Conclusion}

The etiologies of our strictures have not remarkably changed however other stricture characteristics and management have changed over time. A significant number of our patients still present with post inflammatory strictures, although the incidence is also on the decline compared to the past and as noted in other parts of the world. The strictures are however mostly single and bulbar with anastomotic urethroplasty possible in most of the cases.

\section{Declarations}

\section{Ethics and Consent}

Ethical approval was obtained prior to commencement of the study from the Health Research Ethics Committee of Ahmadu Bello University Teaching Hospital Zaria with a reference number of ABUTH/HREC/TRG/36

All patients included in the study were counseled and a written informed consent was signed prior to enrollment into the study.

\section{Competing Interest}

No financial or non-financial competing interest in this study

\section{References}


[1] Mundy AR, Andrich DE. Urethral Strictures. BJU Int 2010;107:6-9.

[2] Alwaal A, Blaschko SD, Mcaninch JW, Breyer BN. Epidemiology of urethral strictures. Transl Androl Urol 2014;2000:209-13.

[3] Mathur R, Nayak D, Aggarwal G, Shukla A, Khan F. A retrospective analysis of urethral strictures and their management at a tertiary care center. J Nephro-Urology Mon 2011;3:109-13.

[4] Xu Y, Song L, Wang K, Lin J, Sun G, Yue Z, et al. Changing trends in the causes and management of male urethral stricture disease in China: an observational descriptive study from 13 centres. BJU Int 2015:938-44.

[5] Oguike TC, Onuora C, Obarisiagbon E. The Changing Pattern of Urethral Stricture Disease in Midwestern Nigeria. UNiBEN JMBR 2006;5:50-4.

[6] Mathur R, Aggarwal G, Satsangi B, Khan F, Odiya S. Comprehensive Analysis of Etiology on the Prognosis of Urethral Strictures. Int Braz J Urol 2011;37:362-70.

[7] Mangera A, Patterson JM, Chapple CR. A Systematic Review of Graft Augmentation Urethroplasty Techniques for the Treatment of Anterior Urethral Strictures. Eur Urol 2011;59:797-814.

[8] Tritschler S, Roosen A, Füllhase C, Stief CG, Rübben H. Urethral Stricture: Etiology , Investigation and Treatments 2013;110:220-6.

[9] Heyns CF, van der Merwe J, Basson J, van der Merwe a. Etiology of male urethral strictures-

Evaluation of temporal changes at a single center, and review of the literature. African J Urol 2012;18:49.

[10] Palminteri E, Berdondini E, Verze P, Nunzio C De, Vitarelli A, Carmignani L. Contemporary Urethral Stricture Characteristics in the Developed World. Urology 2013;81:191-7.

[11] Ekeke ON, Amusan OE. Clinical presentation and treatment of urethral stricture: Experience from a tertiary hospital in Port Harcourt, Nigeria. African J Urol 2017;23:72-7.

[12] Ugezu AM. NA. Urethral Stricture Management Experience at NNewi South East Nigeria 2004;10:107-11.

[13] Osoba A. Gonococcal urethral stricture and watering-can perineum. Br J Veneral Dis 1976:387-93.

[14] Kibukamusoke JW. GONORRHOEA AND URETHRAL STRICTURE *. Br J Veneral Dis 1965;42:135-6.

[15] Ahmed A, Kalayi GD. Urethral stricture at Ahmadu Bello University Teaching Hospital, Zaria. East Afr Med J 1998;75:582-5. 
[16] IC Akpayak, NK Dakum . SONOURETHROGRAPHY IN THE EVALUATION OF ANTERIOR URETHRAL STRICTURE SONOURETHROGRAPHY DANS L ' ÉVALUATION DE rétrécissement De I ' urètre ANTÉRIEUR. J West African Coll Surg 2012;2.

\section{Figures}

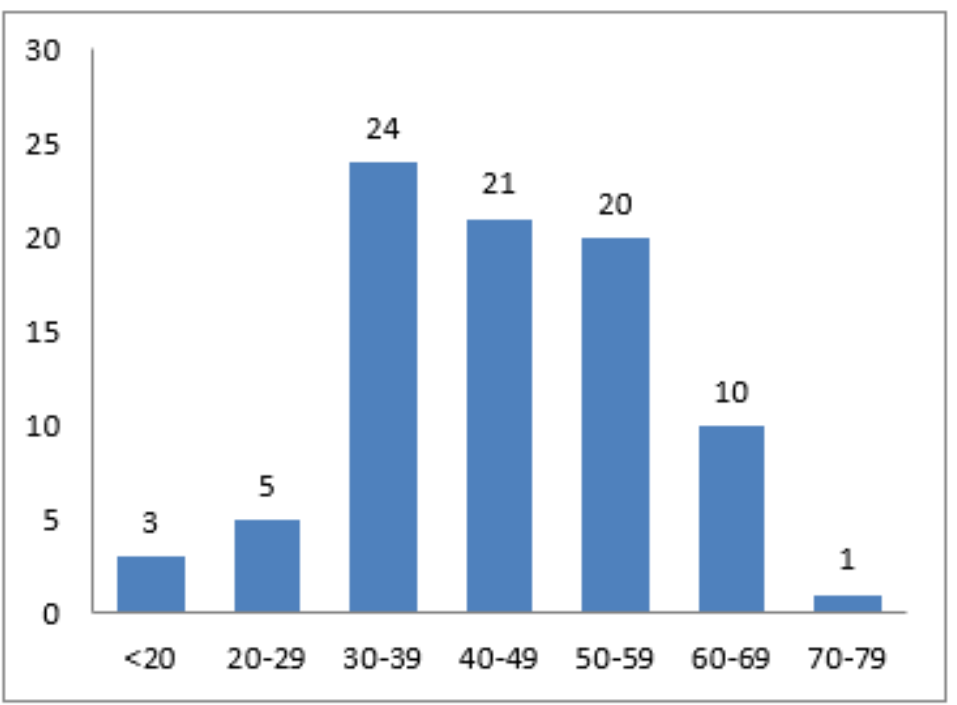

Figure 1

Age distribution of the patients

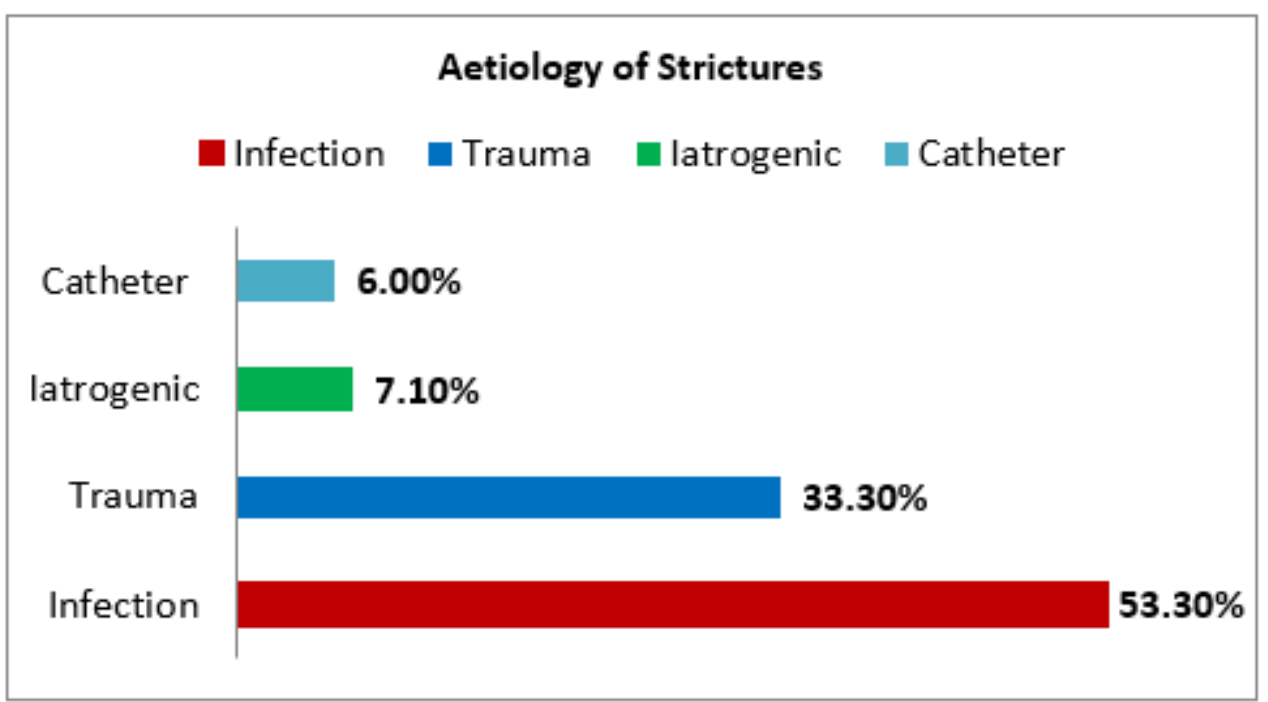

Figure 2

Aetiology of Strictures in the patients 


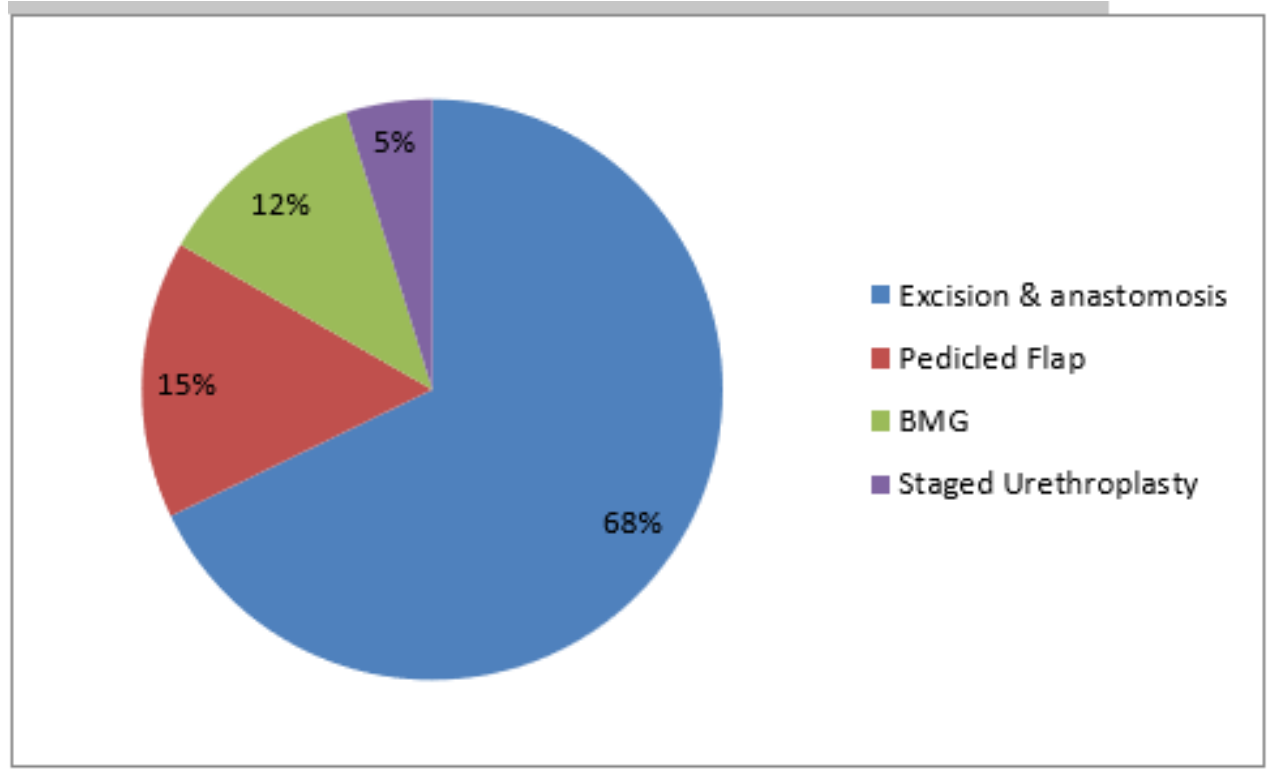

\section{Figure 3}

Management of Urethral Strictures 